DOI: http://doi.org/10.52716/jprs.v11i3.532

\title{
Identification of Drilling Efficiency Using Log-Derived Cation Exchange Capacity in Shale Formation
}

\author{
Ahmed Habeeb Alshamy ${ }^{1, *}$, Faleh H. M. Almahdawi ${ }^{2}$ \\ ${ }^{1,2}$ Department of Petroleum, College of Engineering, University of Baghdad, Iraq \\ *Corresponding Author E-mail: Alshamy1191983@gmail.com \\ dr.f.h.m.almahdawi@coeng.uobagdad.edu.iq
}

Received 22/12/2020, Accepted 3/2/2021, Published 19/9/2021

\begin{abstract}
$\underline{\text { Abstract }}$
Shale and shaly formations constitute about $70 \%$ to $80 \%$ of the total rock formations drilled worldwide, and the most of footage drilled in gas and oil wells is in shale and shaly rocks. Drilling in shale sections in many cases causes wellbore instability and slow drilling problems. In this study, cation exchange capacity of shale is estimated using a relatively simple petrophysical model. The validation of this model is achieved with experimental values of cation exchange capacity. The estimation of cation exchange capacity by this model and common logs data has exhibited potentiality for distinguishing effective/ineffective drilling in shale formations. Drilling and petrophysical data gathered at controlled condition is required in order to optimize the proposed technique. Have knowledge of properties and location of shales permits for remedial actions in future offset well or while drilling in case of logging while drilling (LWD) is used.
\end{abstract}

Keywords: Cation Exchange Capacity, Rate of Penetration, Shale.
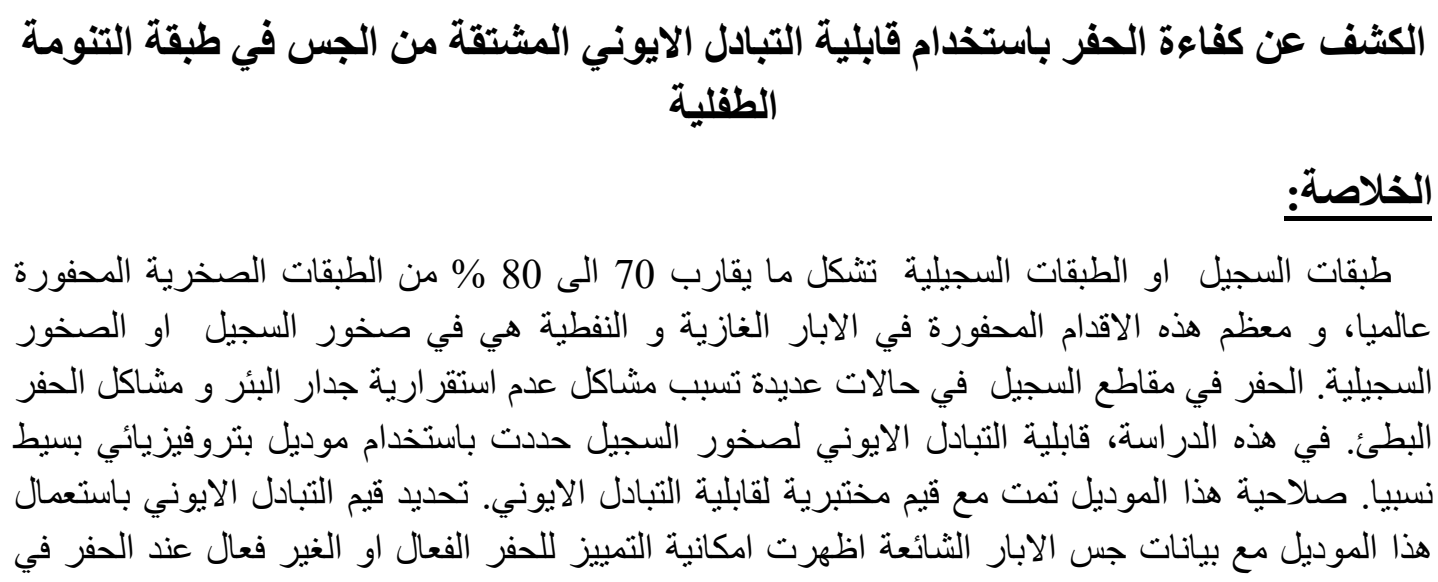
الخلاصة: 
طبقات السجيل. بيانات الحفر و البيانات البتروفيزيائية المجمعة تحت ظروف مسيطرة تكون مطلوبة لتطبيق

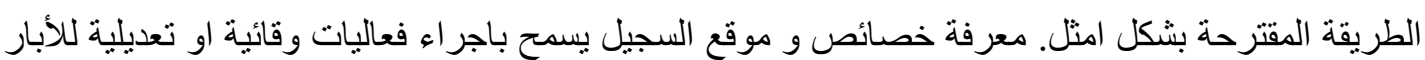

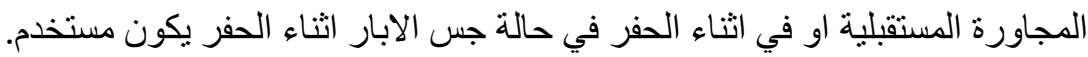

\section{Introduction:}

Optimization of drilling rate plays an important role in reducing of drilling operation expense [1]. Slow drilling/bit balling problem was considered as one of the main causes of ineffective bit performance in case of drilling shale section using water-based mud [2]. The cohesion between shale drill cuttings results in occurring of this problem. Bit efficiency is reduced because of the cuttings agglomeration lead to create a ball. This ball in turn, leads to jam the space between the body of bit and hole-bottom [3].

When the required time for drilling a well increases, the expense is already increases. Furthermore, the rate of penetration (ROP) decreases with increasing of depth in drilling of shale formations [4,5]. Oil and gas industry gives a lot of attention for drilling in the shale formations due to the remedial practice to pass the problems experienced in such formations is by using oil-based mud and polycrystalline diamond compact, PDC, bits. Using a novel inhibitive drilling fluid to reduce the interaction between the water-based mud and sensitive shale rock is considered one of the main keys to performing aims of high levels of wellbore stability, minimize dilution rate, bit balling problem, hole gauge and enhanced economics of drilling operation. Unfortunately, using of a lot of these water-based muds has not prevented the incidents of bit balling and cuttings accretion, in turn will cause in lost time and reducing of drilling rate [12]. Therefore, using these muds for drilling shale formations is not always potential or suitable.

The alternative way in such condition is by using water-based mud and PDC bits [5]. However, the effectiveness of this way has appeared less than the use of oilbased mud with PDC bits. If using water-based mud with PDC bits can be resulted inefficient drilling performance, the expense can be decreased significantly.

Development of drilling performance is one of the main aspects of this study. The slow drilling problem has been investigated by many researchers. Demircan G., Smith J.R and Bassiouni Z. (2000) [3] stated that the low ROP in shale formations 
was related to CEC calculated from log data. They presented a reasonable relationship between the ROP and CEC as helpful mean in diagnosing of drilling performance. Abdolhamid S. and Ali C. (2018) [13] developed a model by correlating the CEC values of the shaly formation with drilling parameters. They mentioned that CEC values of shale formation cannot be directly and continuously measured. Usually, CEC values can be obtained from laboratory or by using empirical relationships from well logs. But, by taking advantage of the logs-derived, using correlations is a beneficial way. They presented a graphical correlation which utilized the drilling parameters and CEC values in order to provide a tool for the prediction of drilling class. Therefore, establishing a method to relate the drilling performance in shale formations with their properties is the main purpose in this study. This proposed method will give the drilling crew an indication of effective or ineffective drilling at given time. Consequently, it will help the drilling crew to choose the corrective actions to increase the ROP in order to decrease the drilling expenses. In other ward, it is capable of driller to detect the drilling rate and to preserve it at efficient level.

\section{Data preparation}

Field data (drilling and well logs data of well GR-130 and G-38) was obtained from shale formation in a southern Iraqi oilfield used to exemplify of this problem in this study. The all necessary petrophysical and drilling data is available for well G130 and G-38. Fundamental drilling parameter available of wells involve rate of penetration (ROP), rotary speed (RPM), weight on bit (WOB), hydraulic data, and torque. The needed petrophysical data include gamma ray, resistivity logs, neutron and density porosity logs are also available.

\section{Geological background of studied Field}

An Iraqi oilfield is situated in southern of Iraq in Thi-Qar governorate about (85 $\mathrm{km}$ ) to the north of Nassiriyah city Figure (1) [14]. It was discovered in 1984. The field's structure is $(10 \mathrm{~km})$ width and $(31 \mathrm{~km})$ length, gently dipping low relief anticline with a trend extends in North-West to South-East direction [14][15]. It has proven by exploration and appraisals wells, that it has a hydrocarbon accumulation 
in primary oil accumulation zones in the Mishrif and Yamama Formations. Mishrif formation contains $70 \%$ of field's reserve, and secondary accumulations, which are existed in Zubair and Ratawi formations. Figure (2) shows the geographic location of the field.

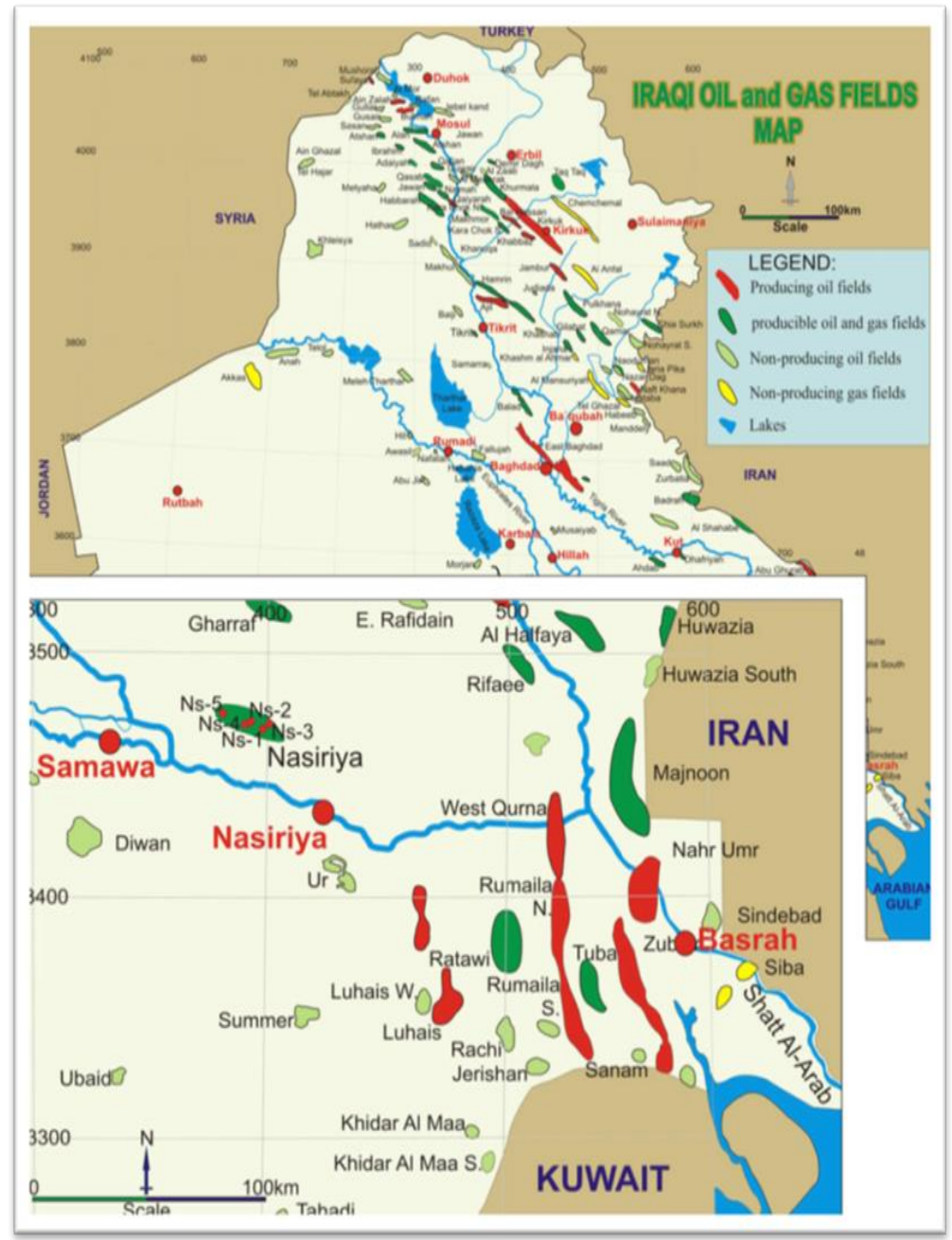

Fig. (1) Oilfield Location 


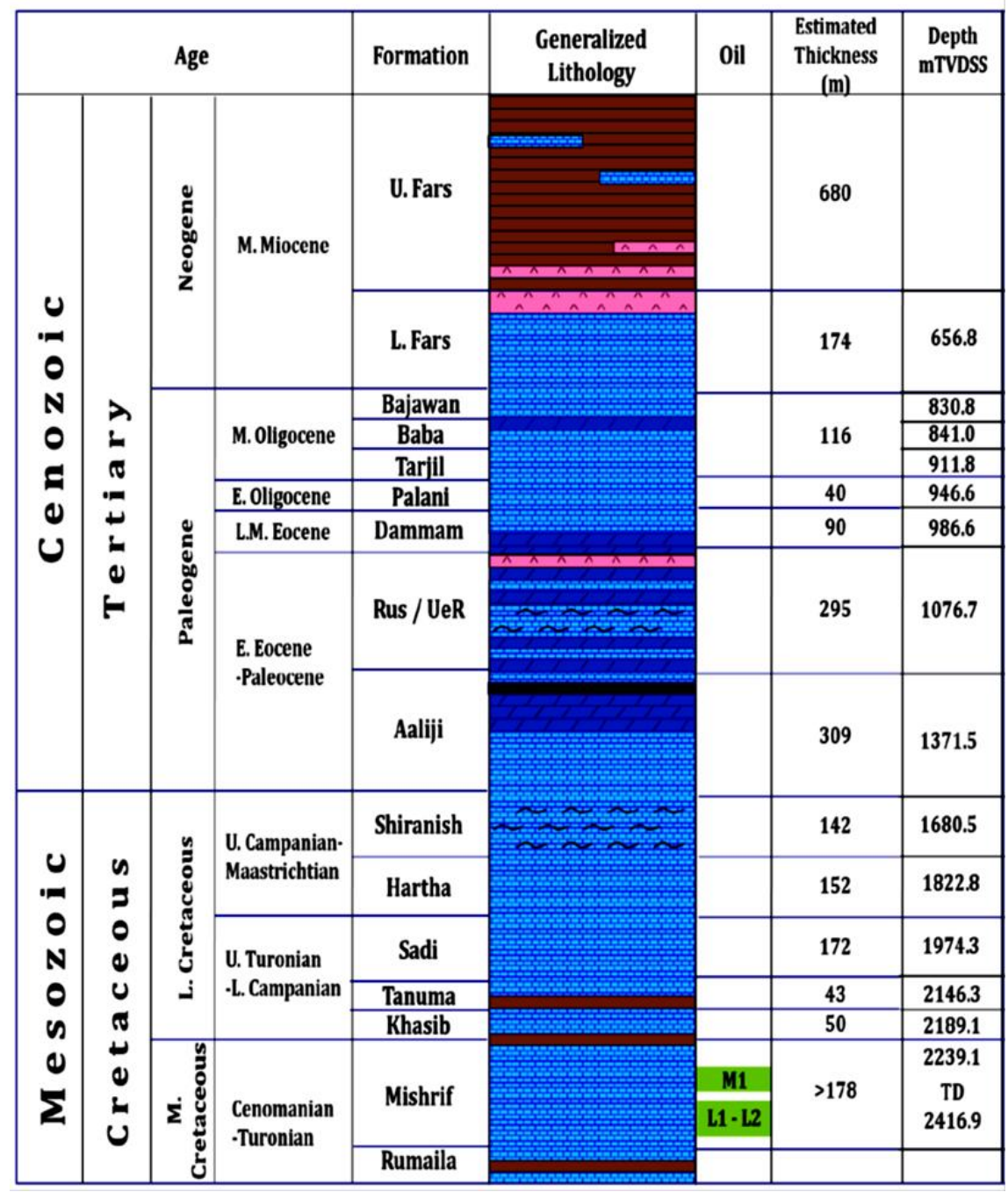

Fig. (2) Lithological column of the Oilfield.

\section{Petrophysical model of CEC Estimation:}

Considerably, the clay type influence on drilling efficiency, a petrophysical model was applied to relate cation exchange capacity (CEC) with shale characteristics commonly estimated using logs technique, applicable petrophysical data with drilling date lead to present an application for potential drilling optimization.

Waxman-Smits shaly sand model is considered as parallel bound water and far water conductivity equation which is presented as following [6]:

$$
\frac{1}{R_{o}}=\frac{1}{F^{*}}\left[\frac{1}{R_{w}}+B Q_{v}\right]
$$


Where:

$\mathrm{R}$ : is the resistivity of the water bearing shaly sand, ohm-m.

$\mathrm{F}^{*}$ : is the formation factor of the shaly sand.

$\mathrm{R}_{\mathrm{w}}$ : is the resistivity of the far water, ohm-m.

$\mathrm{B}$ : is the equivalent counterion conductance, $\mathrm{mho} / \mathrm{m}(\mathrm{meq} / \mathrm{cc})$, and

$\mathrm{Q}_{\mathrm{V}}$ : is the counterion concentration, meq /cc pore volume.

Using the perfect shale concept, which assumes that all the electric conductivity is due to bound water [7], the above equation reduces to:

$\frac{1}{R_{s h}}=\frac{1}{F_{s h}}\left(B_{\max } Q_{v}\right)$

Where: $F_{s h}$ and $R_{s h}$ are the shale formation resistivity factor and resistivity respectively. $\mathrm{B}_{\max }$ is the maximum equivalent counterion conductance.

Solving for Q yields:

$Q_{v}=\frac{F_{s h}}{R_{s h} B_{\max }}$

$Q_{v}$ is related to cation exchange capacity by [8]:

$Q_{v}=C E C \frac{1-\emptyset_{t}}{100 \emptyset_{t}} \rho_{m a}$

Where:

$\emptyset_{t}$ : Total porosity, fraction.

$\rho_{m a}:$ is the density of rock matrix containing shale, $\mathrm{g} / \mathrm{cc}$, and

CEC: is the cation exchange capacity, meq/100 gm.

To calculate $\mathrm{Q}_{\mathrm{v}}$ and CEC using $\log$ data, $\mathrm{R}_{\mathrm{sh}}, \mathrm{B}_{\mathrm{max}}, \rho_{\mathrm{ma}}$ and $\mathrm{F}_{\mathrm{sh}}$ have to be estimated. $\mathrm{R}_{\mathrm{sh}}$ can be read directly from electric logs. $\mathrm{B}_{\max }$ can be calculated using the following correlation derived from experimental data collected by Waxman and Thomas [9]:

$\mathrm{B}_{\max }=0.0003 \mathrm{~T}^{2}+0.205 \mathrm{~T}-0.0929$

Where: 
$\mathrm{T}$ : is the temperature of zone of interest, $C^{\circ}$.

$\mathrm{B}_{\max }$ : is the maximum equivalent counterion conductance, $\mathrm{mho} / \mathrm{m} /(\mathrm{meq} / \mathrm{cc})$.

Dual water model [10], the total porosity is calculated as an average of the density and neutron porosity i.e.:

$\emptyset_{t}=\frac{\emptyset_{\text {neutron }}+\emptyset_{\text {density }}}{2}$

The shale formation factor is then calculated by [10]:

$\mathrm{F}_{\mathrm{sh}}=\emptyset_{t}^{-2}$

Figure (3) and (4) illustrates the results of the log-derived CEC with depth for well G-130 and G-38 respectively. 
Journal of Petroleum Research and Studies

Open Access

jopge

P- ISSN: 2220-5381

No. 32, September 2021, pp.48-65

E- ISSN: 2710-1096

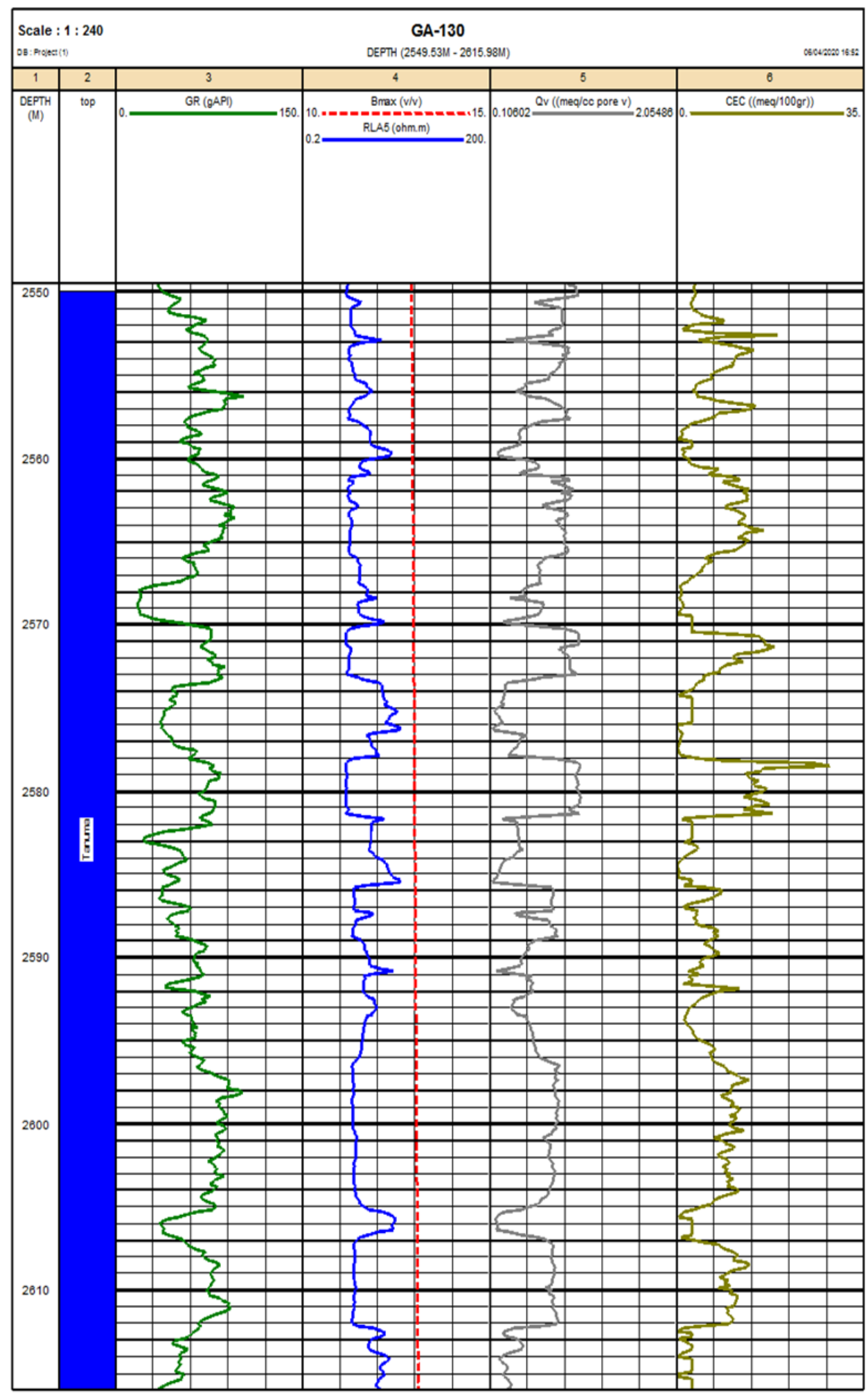

Fig. (3) Log-derived CEC results for well G-130. 
Journal of Petroleum Research and Studies

Open Access

jopg

P- ISSN: 2220-5381

No. 32, September 2021, pp.48-65

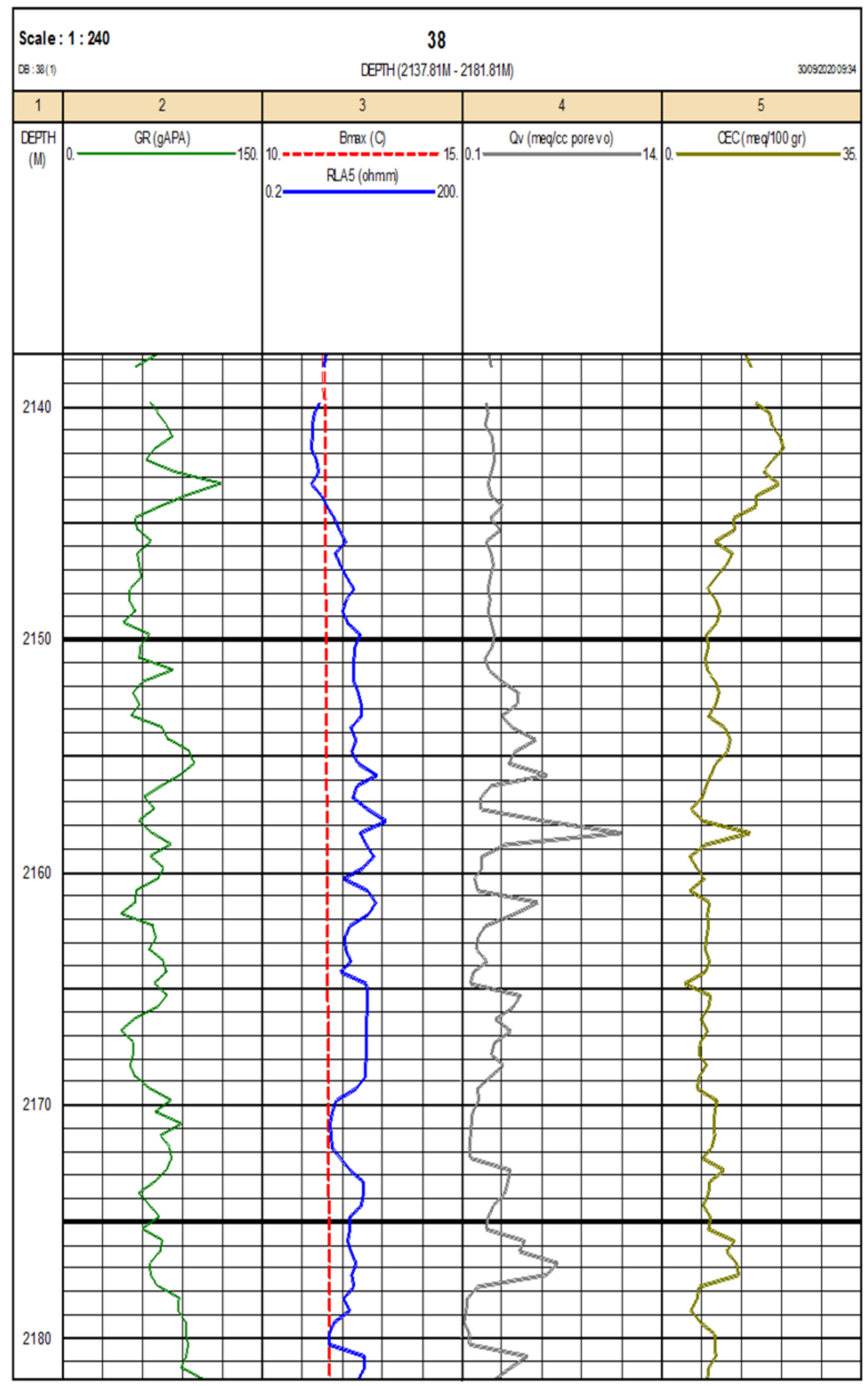

Fig. (4) Log-derived CEC results for well G-38. 


\section{Experimental Measurements of CEC:}

The cation exchange capacity (CEC) measurements were accomplished on drill cuttings samples only available for well G-130.

The cation exchange capacity values were measured using blue methylene test for the available drill cutting samples which were taken for the interval 2560 to $2567 \mathrm{~m}$ of well G-130, and the results are shown in Table (1). Then, the measured values were compared with CEC values estimated using equation (4) and log data. The comparison between calculated and measured CEC values is illustrated in Figure (5). The R2 coefficient showed in Figure (3) can be considered reasonable with the measured values and with the unusual uncertainty for the logs values particularly those of shale [3].

Table (1) Measured CEC, meq/100gm

\begin{tabular}{|c|c|}
\hline Depth $(\mathrm{m})$ & Measured CEC \\
\hline $2340-2343$ & 9.2 \\
\hline $2560-2561$ & 6.2 \\
\hline $2561-2562$ & 9.3 \\
\hline $2562-2563$ & 11.6 \\
\hline $2563-2564$ & 10.5 \\
\hline $2564-2565$ & 12.8 \\
\hline $2565-2566$ & 10.8 \\
\hline $2566-2567$ & 7.12 \\
\hline $2567-2568$ & 7.2 \\
\hline
\end{tabular}

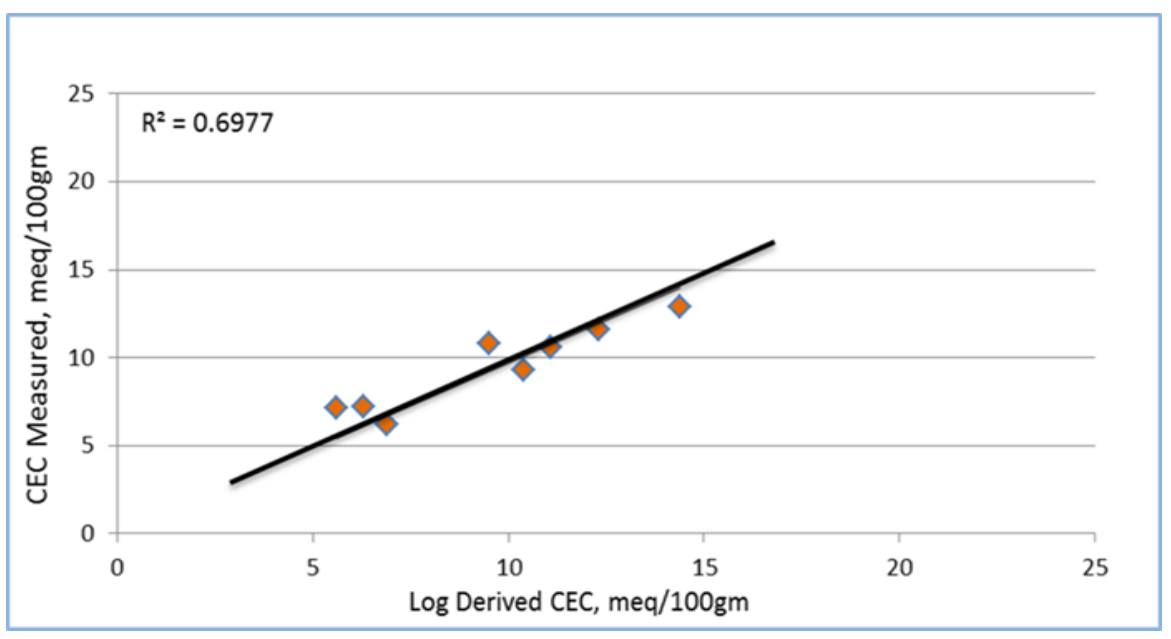

Fig. (5) Log-derived CEC results for well G-130. 


\section{Normalized Rate of Penetration (ROPn):}

The ROP normalization is has to be achieved in order to combine and compare data from various drilled intervals and drilled wells. The following model is used to normalize the ROP [11]:

$R O P_{n}=\frac{R O P_{\text {actual }}}{\left(\frac{W O B}{d_{b}}\right)^{2}\left(\frac{N}{60}\right)}$

Where;

$R O P_{\text {actual }}:$ Rate of penetration, fph.

$R O P_{n}$ : Normalized rate of penetration.

$d_{b}:$ Bit diameter, inch.

WOB : Weight on bit, klbf.

$N$ : Rotary speed, rpm.

\section{Correlation of ROP $_{n}$ with Log-Derived CEC:}

Figures (6) and (7) represent a plot of ROP vs. estimated CEC, and Figures (8) and (8) illustrate the normalized ROPn vs. estimated CEC for G-130 and G-38 respectively. The figures of ROP and ROPn vs. CEC calculated display two distinctive trends one represents ineffective drilling trend and the other represents effective drilling trend. The plots show a good clarified pattern for efficiently drilled shale. The points falling off the pattern are expected to drill with cleaner bit. A lack in trend for slow drilling in shale is expected because when the bit is balled, there are little relationships between the formation characteristics and drilling performance.

Figures (6) to (9) propose a plot technique of early identifying for slow drilling problem or bit balling. When the drilling performance first falls off the effective drilling pattern (clean bit), the drilling crew will be cautioned concerning a drilling performance problem which may got worse if not correctly addressed. Therefore, implementing of this method is accomplished by estimating the CEC derived from logs data acquired while drilling. 


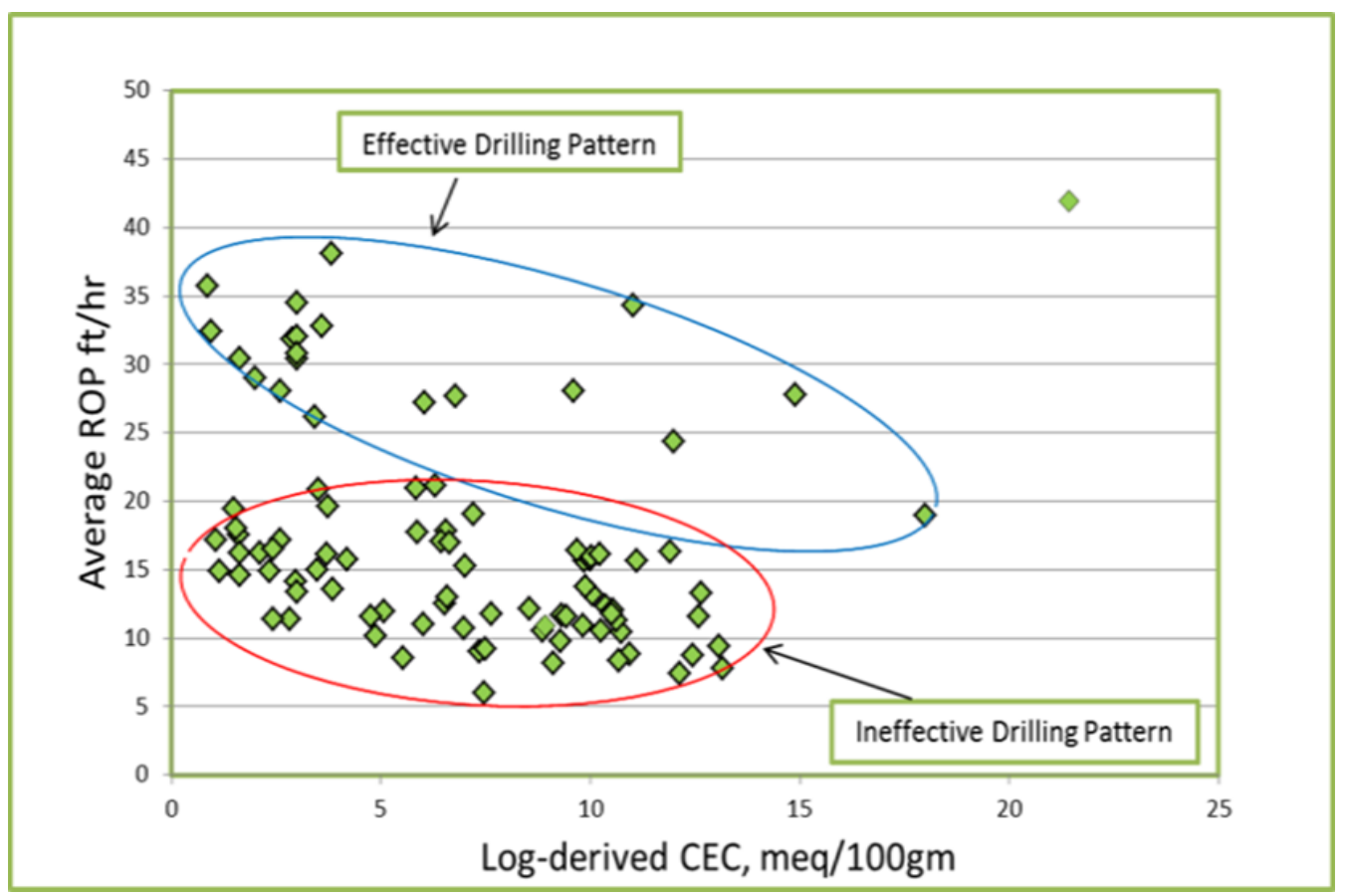

Fig. (6) ROP versus log-derived CEC plot for well G-130.

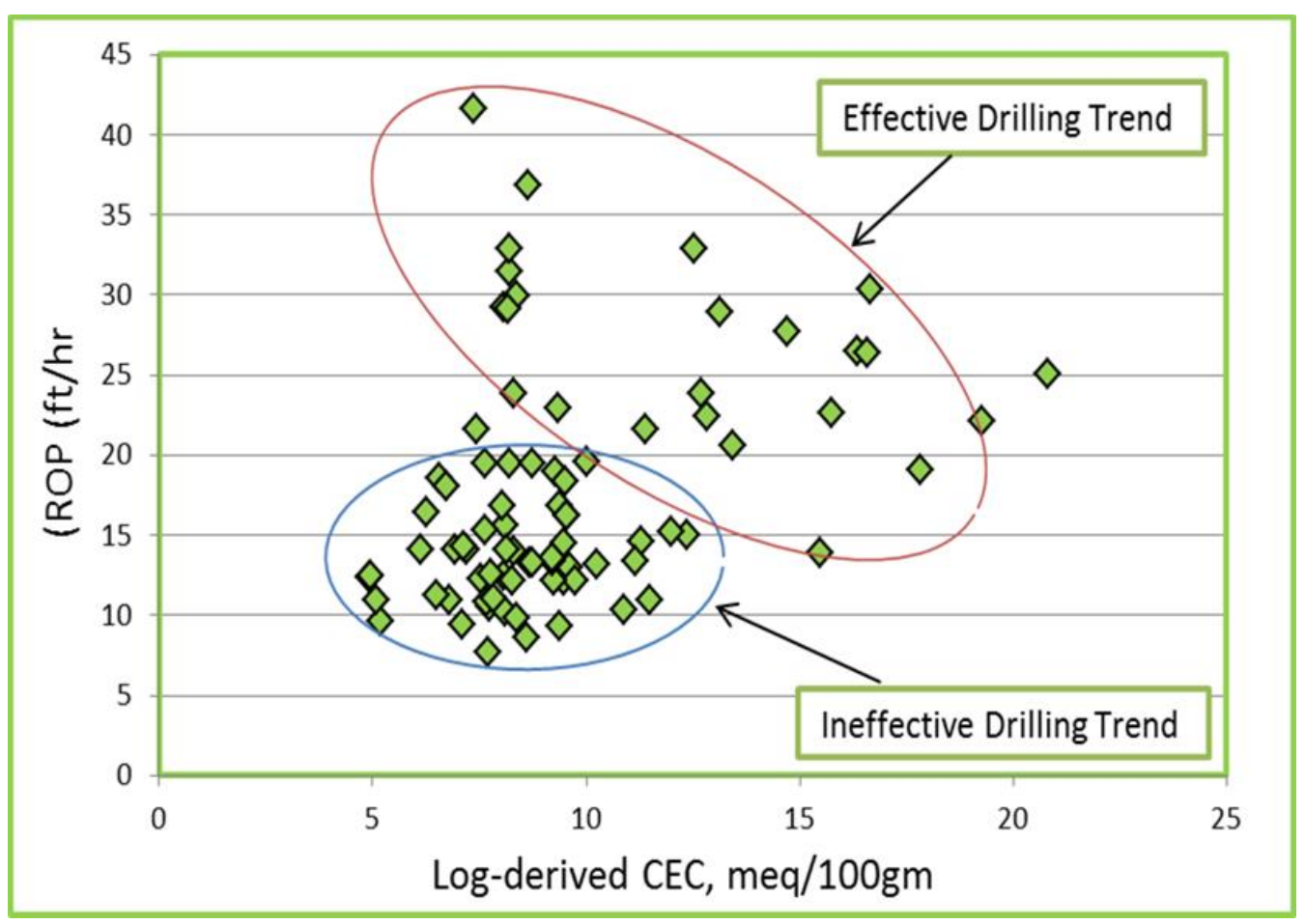

Fig. (7) ROP versus log-derived CEC plot for well G-38. 


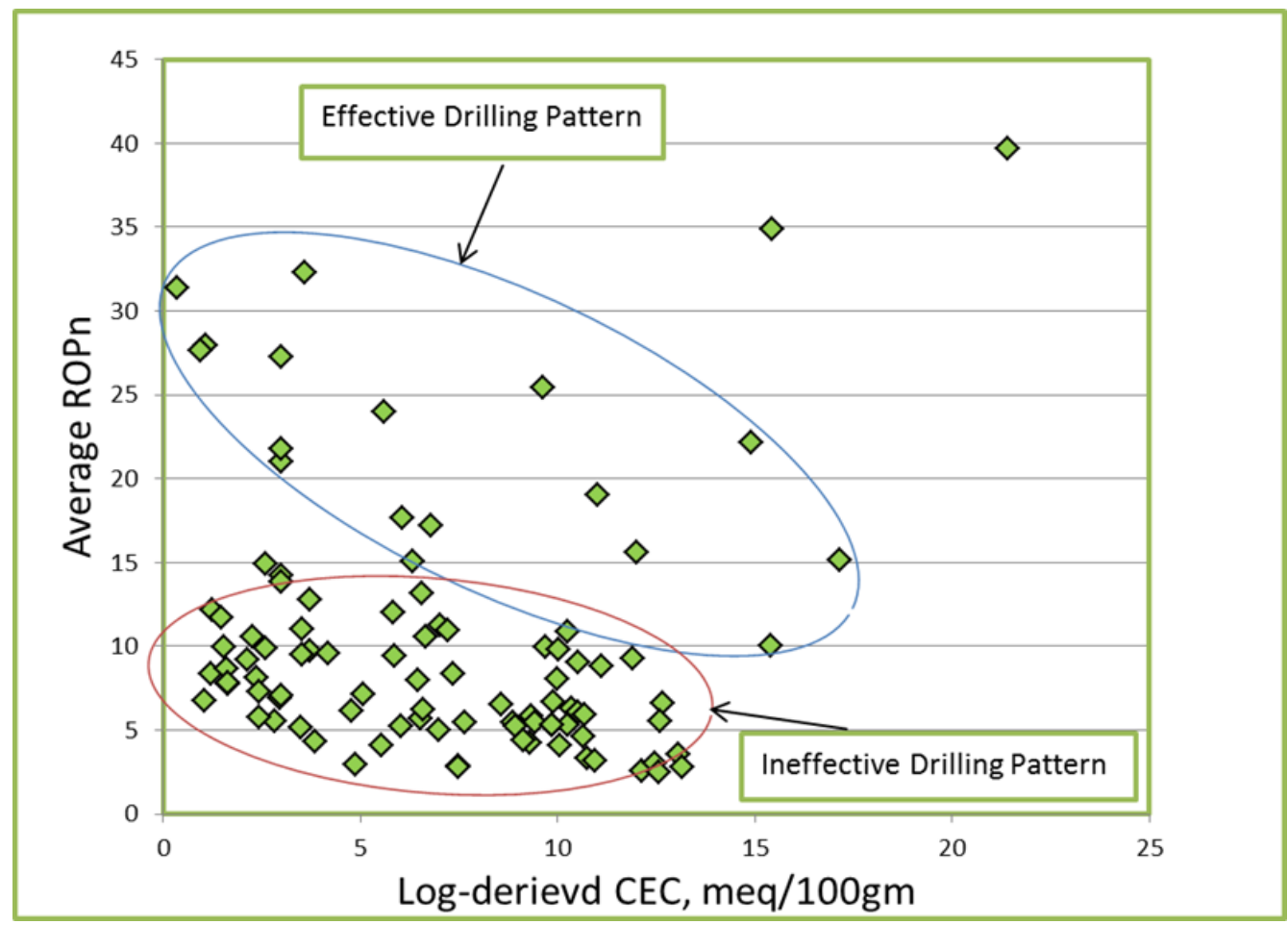

Fig. (8) ROPn vs. log-derived CEC for well G-130.

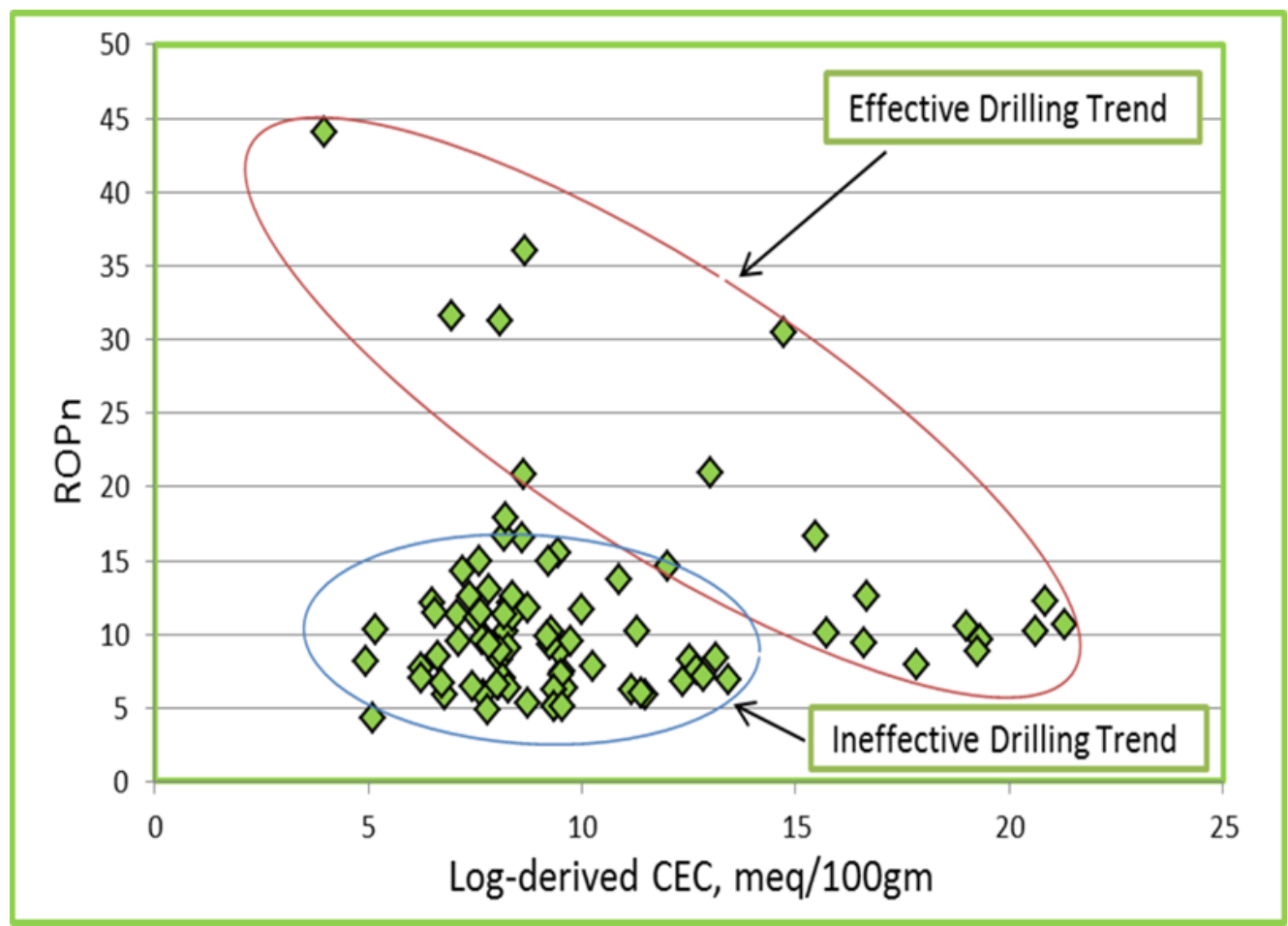

Fig. (9) ROPn vs. log-derived CEC for well G-38. 
Figure (10) is a plot of ROPn vs. log-derived CEC for well G-130 along the Tanuma interval. For example, this plot displays three zones of concern. Zone A is characterized by relatively low of ROPn and relatively high CEC, thus it is clearly represented the slow drilling performance. Slow drilling problem is apparently diminished by applying a relatively low weight on bit (WOB) and by bit cleaning returning the ROP at extremely high level as it drilled in sandy streaks. Zone B exhibited the highest ROPn values and relatively low CEC values and also displays the starting of a decrease in drilling performance because of bit balling effect and continued to impact the drilling performance as showed in zone $\mathrm{C}$, in spite of decreasing CEC values in some regions. Zone B represents the effective drilling trend. So, the falling off from such trend in shale drilling provides a warning sign to the drilling crew that the reducing in ROP is because the high CEC values rather than a strong rock. 
Journal of Petroleum Research and Studies

Open Access

No. 32, September 2021, pp.48-65

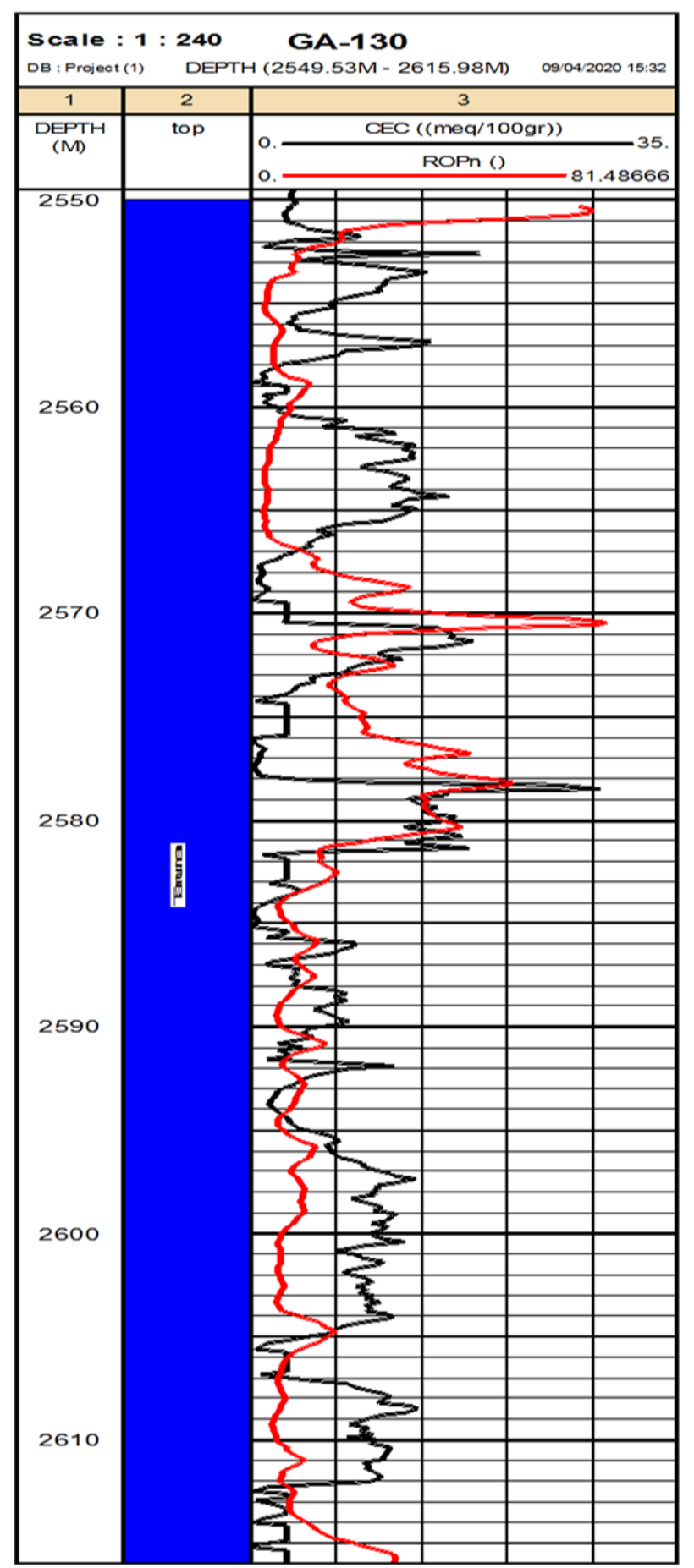

Fig. (10) Log-derived CEC vs. ROPn with Depth for Well G-130. 


\section{Conclusion:}

A shale cation exchange capacity (CEC) values were estimated using a simple petrophysical model from log data. A reasonable correlation between Log-derive CEC of shale and effective drilling rate of penetration was performed. When a trend of normalized rate of penetration $\left(\mathrm{ROP}_{n}\right)$ vs. log-derived cation exchange capacity value (CEC) values is created during drilling operation, divergence of that trend can provide a warning of slow drilling/bit balling.

The petrophysical and drilling data used to estimate CEC values and test the suggested warning technique are ordinary. In the case of data gathered at controlled conditions, investigation of the proposed warning approach will be developed. Application of this technique in field through drilling can optimize drilling operation by diagnosing the drilling performance in order to preserve the rate of penetration at effectively rates and to overpass the slow drilling problem in Tanuma shale.

\section{Nomenclatures:}

ROP: Rate of penetration

ROPn: Normalized rate of penetration.

CEC: Cation exchange capacity.

$\mathrm{R}^{2}$ : Correlation Coefficient.

WOB: Weight on bit.

RPM: Rotation per minute. 


\section{$\underline{\text { References: }}$}

[1] Mnati, Kadhim Hmood, and Hassan Abdul Hadi. "Prediction of penetration Rate and cost with Artificial Neural Network for Alhafaya Oil Field." Iraqi Journal of Chemical and Petroleum Engineering 19, no. 4 (2018): 21-27.

[2] Smith John Rogers. "Diagnosis of Poor PDC Bit Performance in Deep Shales." (1998).

[3] Demircan Guncel, John R. Smith, and Zaki Bassiouni. "Estimation of Shale Cation Exchange Capacity Using Log Data: Application to Drilling Optimization." In SPWLA 41st Annual Logging Symposium. Society of Petrophysicists and WellLog Analysts, 2000.

[4] Smith John Rogers. "Drilling Over-Pressured Shales with PDC Bits: A Study of Rock Characteristics and Field Experience Offshore Texas." PhD diss., PhD Thesis, Louisiana State University, 1995.

[5] Smith John Rogers. "Addressing the problem of PDC bit performance in deep shales." In IADC/SPE Asia Pacific Drilling Technology. Society of Petroleum Engineers, 1998.

[6] Waxman, Monroe H., and L. J. M. Smits. "Electrical conductivities in oilbearing shaly sands." Society of Petroleum Engineers Journal 8, no. 02 (1968): 107122.

[7] Silva, Pedro L. "Development of a New Conductivity Model for Shaly Sand Interpretation." (1986).

[8] Desbrandes, Robert. Encyclopedia of well logging. Editions OPHRYS, 1985.

[9] Waxman M. N. and Thomas C. E., "Electrical Conductivities in Oil-bearing Shaly Sand, The Relation between Hydrocarbon Saturation and Resistivity Index," The temperature coefficient of electrical conductivity: Society of Petroleum Engineers Journal, 1974, 14, 213-225.

[10] Clavier, C., George Coates, and J. Dumanoir. "Theoretical and experimental bases for the dual-water model for interpretation of shaly sands." Society of Petroleum Engineers Journal 24, no. 02 (1984): 153-168.

[11] Demircan, Guncel, John R. Smith, and Zaki Bassiouni. "Estimation of Shale Cation Exchange Capacity Using Log Data: Application to Drilling Optimization." 
In SPWLA 41st Annual Logging Symposium. Society of Petrophysicists and WellLog Analysts, 2000.

[12] Mettath, Sashikumar, Emanuel Stamatakis, Steven Young, Guido De Stefano, and MI SWACO. "The Prevention and Cure of Bit Balling in Water-Based Drilling Fluids." American Association of Drilling Engineers (2011).

[13] Sameni Abdolhamid, and Ali Chamkalani. "The application of least square support vector machine as a mathematical algorithm for diagnosing drilling effectivity in shaly formations." Journal of Petroleum Science and Technology 8, no. 1 (2018): 3-15.

[14] TOC, "End of Well Report (Ga-X40P)",PCIIHBV, Ar Rifa'I, Dhi Qar, rep.,2018.

[15] Dd M. Embong, M. Higashi, H. H. Abu Baker, K. A. Zamri, F. H. M. Ali, S. Moryia, S. B. M. Said, and A. T. Patrick Panting, " Petroleum Geoscience Conference \& Exhibition 2012", in Reservoir Characterization of Mishrif Formation of Garraf oilfield, Iraq, using 3D seismic and AI Inversion, 2012. 